\title{
Validating Simulation Analysis of Solar PV System Assessment for Residential Buildings using Homer Software
}

\author{
Srikant Misra, G R K D Satya Prasad, Ch. Saibabu, Rakesh Sahu
}

\begin{abstract}
The local supply and supply scheme called micro grid will become a significant chance due to the latest development of small scale distributed generators such as $\mathrm{OV}$ on demand side. Renewable energy structure has been far reaching due to ecological demands. The essence of the structure for renewable energy is very efficient in using distributed generation within the structure of the power scheme. The low voltage DC distribution system is becoming essential as the amount of DC applications is increasing in our regular needs. Power provided through the $A C$ distribution mechanism of low voltage requires both AC/DC converter to delivers the DC batteries. MGs would be fitted battery like energy storage devices. Since PVs and batteries primarily operates through $D C$, it is possible to emphasize the benefit of the DC distribution scheme over AC production. This article recommends an ideal MG layout including $A C$ and $D C$ distribution device choice. This article also describes qualitatively the benefit of micro grid with DC production, termed as DCMG through housing client studies assuming different kinds of home appliances.
\end{abstract}

Keywords: AC \& DC micro grid, Distributed Generation, Micro grid,

\section{INTRODUCTION}

The use of renewable energy such as PV in power system is increasing to reduce environmental loading. Another tendency in technological growth is microgrid, which can incorporate the RE production efficiently into a local energy distribution scheme. PV production is changeable and intermittent based climate conditions, however it is therefore hard to replace PV system immediately from the utility grid for standard power supply. With the growing spread of renewable energy sources and energy storage scheme, electrical power scheme development is focused on growing green technology usage. Two frequently recognized green energy sources are the photovoltaic system and wind turbine.

Revised Manuscript Received on October 30, 2019.

* Correspondence Author

Srikant Misra*, Asst. Professor in EE Department, GIET University, Gunupur, India. srikantm@giet.edu

G R K D Satya Prasad, Department of EEE, GIET University, Gunupur, India. grkdsp@giet.edu

Dr. Sai Babu. Ch. Professor in EEE Department, JNTUK, Kakinada, India

Rakesh Sahu, Asst. Professor in EE Department, GIET University, Gunupur, India. rakeshsahu@giet.edu

(C) The Authors. Published by Blue Eyes Intelligence Engineering and Sciences Publication (BEIESP). This is an open access article under the CC BY-NC-ND license (http://creativecommons.org/licenses/by-nc-nd/4.0/)
Number of power electronics transformation phases are required to incorporate these renewable sources with the exiting alternative current distribution grid. This leads to the difficulty and also impacts the system relative performance. Due to reduced power conversion phases, the DC distribution system can attain greater effectiveness. The use of DC appliances has increased quickly in home and business apps. Most systems use DC externally, requiring AC to DC transformation between the appliances and AC production. Combination with an energy storage scheme (ESS) as batteries is researched to acknowledge PV as a strong generation asset. The basic concept of ESS reward is to accumulate the excess power from PVs and release it when the output of PVs becomes low. On the other side, from an economic point of view, the ESS should pay weekends and daytime disposal because overnight tariffs are generally lower than daytime. That is, there are fundamental conflict between the stability of PV energy and the financial activity. It is significant to schedule the ESS procedure in advance, taking into account the PV output prediction and demand forecast and so on, for an acceptable use of ESS in the contest of MG. In order to obtain cost effectively and environmentally friendly production of electricity, it is essential to properly develop MG parts taking into account the demand characteristics. This article proposes optimizing MG sizing depending on discrete programming and formulating MG sizing as a hybrid integer parameter programming in which components can be selected from limited amount of choices. On the other hand, DC is naturally used by PVs and some ESSs. However, as standard business system utilizes AC based PV system and charging / discharge energy of ESSs are transferred into AC. Furthermore, some home appliances such as lamps and electronics equipment use DC. They also involve transformation of AC/DC. Since transitions between $\mathrm{AC}$ and DC output transformation failures, there is a need to reduce the amount of converters. An alternative would be to implement of DC scheme. A DC scheme would also offer other benefits such as improving production efficiency and reducing occupancy region of parts. This document contrast AC based MG and DC based MG schemes quantitative basis.

\section{MICRO GRID}

A micro grid is a set of organized supplies and dispersed energy resources within obviously specified electrical limits, acting as a single manageable grid organization. A microgrid can plug and disconnect from the web to allow both grid connected and island mode operation. 
A microgrid is localized set of inputs and bundles of energy that usually works linked and synchronous with traditional broad region synchronous system, but can also disconnect to island mode - and operate autonomously as directed by physical and financial circumstances. In this manner, a microgrid can efficiently incorporate multiple distributed grid (DG) systems, particularly Renewable Energy Sources (RES) - solar energy can deliver urgent energy.Control and security are microgrid difficulties. A very significant characteristic is also to provide various end use requirements such as thermal, ventilation and electricity at the same moment as tis enables energy carrier replacement and enhanced energy efficiency owing to waste heat utilization for cleaning, warm water and ventilation reasons.This document implies, alternatively, the DCMG and ACMG scheme setup shown in fig 01 and 02. The two MGs consist of PV system and a battery system as source of electricity for two types of charges AC and DC charges. The DCMG is linked to the utility via an interface rectifier that can transform electricity from AC to DC only way. Because the daytime and nighttime charge of electricity is assumed to be different in this paper. MG cannot buy the excess energy to assess the ESSs reward capacity. The battery must therefore withstand unnecessary PV production, which is greater than complete supply as frequent restriction of PV production is technological impractical.

\section{SCHEME OF DC MICROGRID SYSTEM:}

Radial storage scheme, ring delivery scheme or interconnected delivery scheme can be the grid design of DC distribution system. The delivery system structure and layout determine the accessibility and sensitivity to faults. A radial distribution network has reduces the availability of faults and on the contrary a meshed network has a higher availability but is more vulnerable to faults. In meshed network, it is likewise even more twisted to control the power flow.The purpose of DC microgrid scheme is to be incorporated into the construction as shown in fig 01. This article considers DC origin such as batteries and PV modules to evaluate the general system efficiency. Using a buck converter or step down chopper, the break down voltage is transformed to DC. A common $30 \mathrm{~V}$ bus is linked to loads of various kinds. Similarly, the voltage is $24 \mathrm{~V}$ for moving charge and the DC/ $\mathrm{DC}$ converter is used again to move down from $30 \mathrm{~V}$ to $24 \mathrm{~V}$.

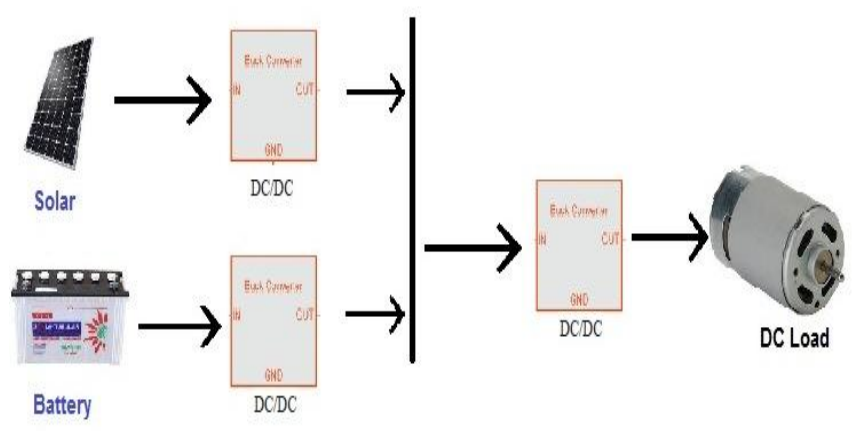

Fig No 01: DC Micro Grid

\section{SCHEME OF AC MICROGRID SYSTEM:}

The new single phase $230 \mathrm{~V}$ RMS AC voltage range is considered for AC microgrid scheme. The AC charges can be provided straight from the AC grid. AC-DC converter can be used to connect DC batteries, accompanied by DC-DC converter. Fig 2 shows the ACMG schematic diagram with both AC and DC inputs. Starting from the $230 \mathrm{~V}$ single phase primary voltage, it is straight linked with the AC bus. The using a buck converter or step down chopper, breakdown voltage is transformed to DC. Then DC converters to AC from the batteries scheme ad connects to the AC bus. AC charges are powered from immediate AC bus, while DC loads attached to AC bus via Ac to DC converter and DC/DC converter.

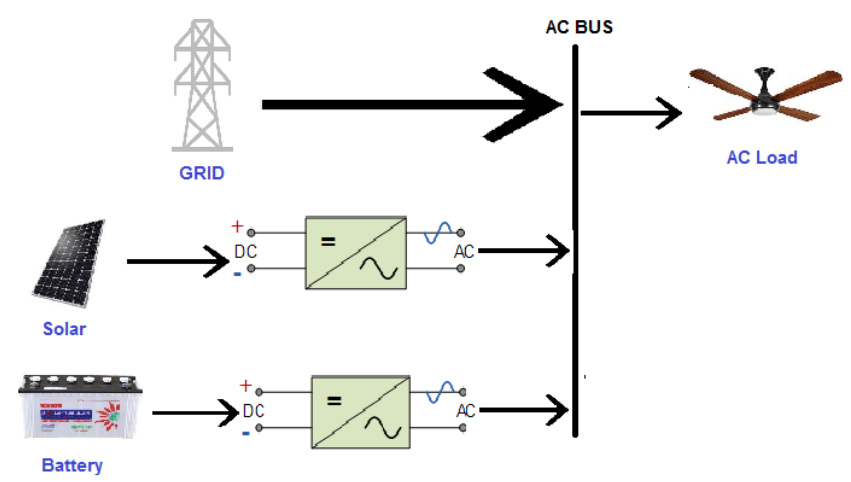

Fig No 02: AC Micro Grid

VI. SIMULATION AND MODEL:

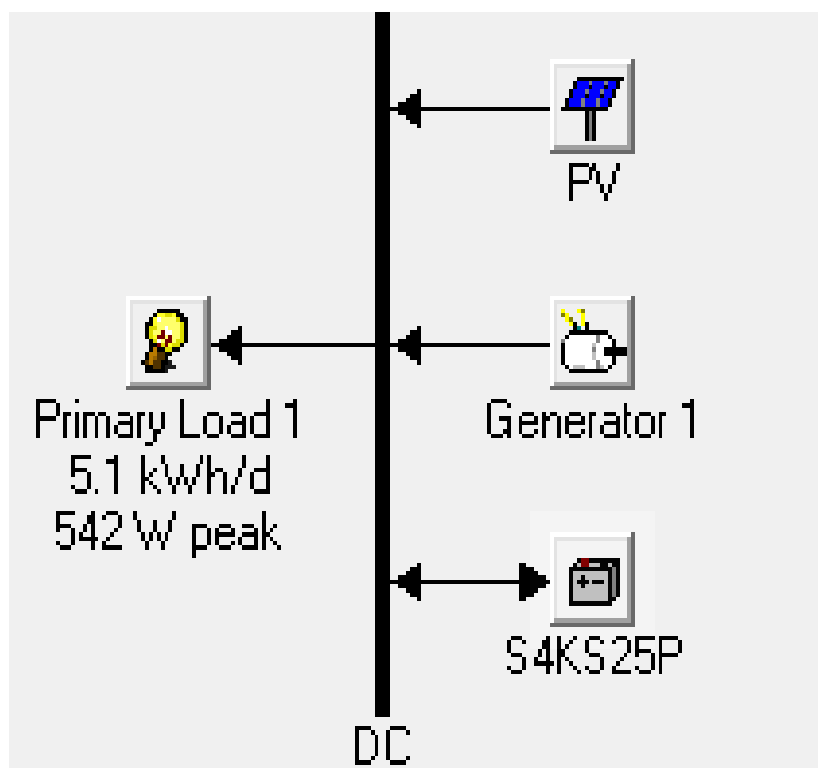

Fig No 03: Homer model for DC Micro Grid

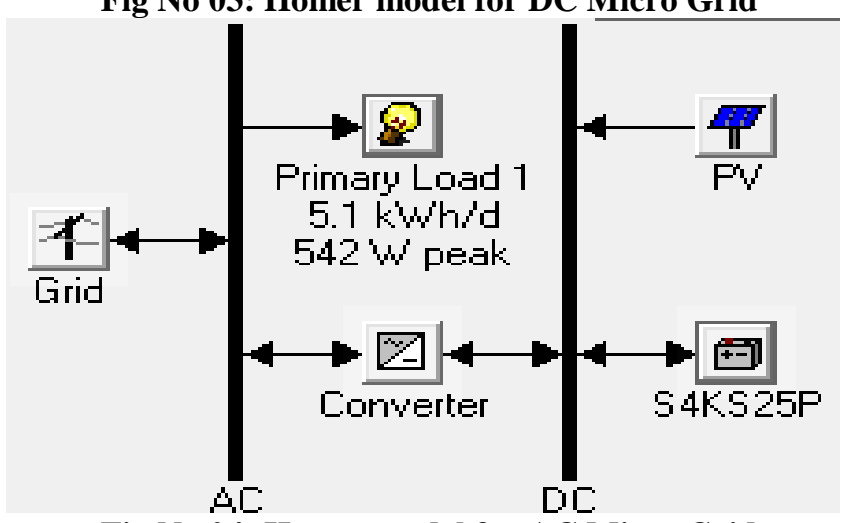

Fig No 04: Homer model for AC Micro Grid

Published By:

Blue Eyes Intelligence Engineering \& Sciences Publication 
Figure number 03 and 04 are the experimental model of DC Microgrid and AC Microgrid with the help of HOMER 3.1. The experimental setup for DC Microgrid contains a standalone PV system with $1.25 \mathrm{KW}$ size, a high depth battery with rating $12 \mathrm{~V}-150 \mathrm{AH}$ and $1 \mathrm{KW}$ standby diesel generator. The setup for AC Microgrid contains a grid connected PV system with 1.25 KW size and a high depth battery with rating $12 \mathrm{~V}-150 \mathrm{AH}$.

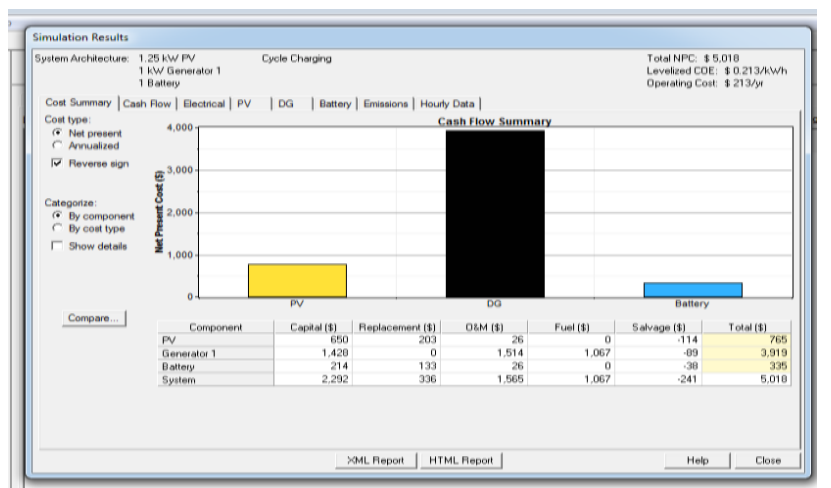

Fig No 05: Cash flow for individual arrangement of DCMG

Figure 5 explains the cash utilization to setup the exaperimantal setup of DC microgrid where involvement of solar, DG set and battery bank. The total install value is arround 2200 dolar.

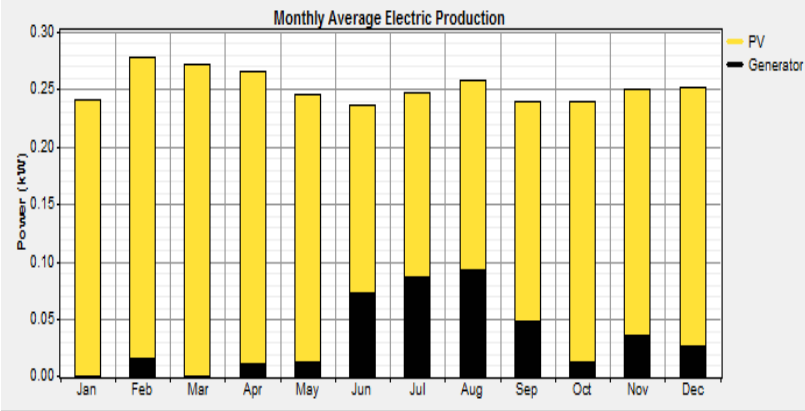

Fig No 06: Monthly Average electricity production of DCMG

Total electricity production by all the unit of sources are explained in the figure number 06. From this figure we can analyze that maximum electricity is being produced by solar standalone system. During cloudy days the backup is controlled by DG set. The value from DG set very less as compared to solar system.

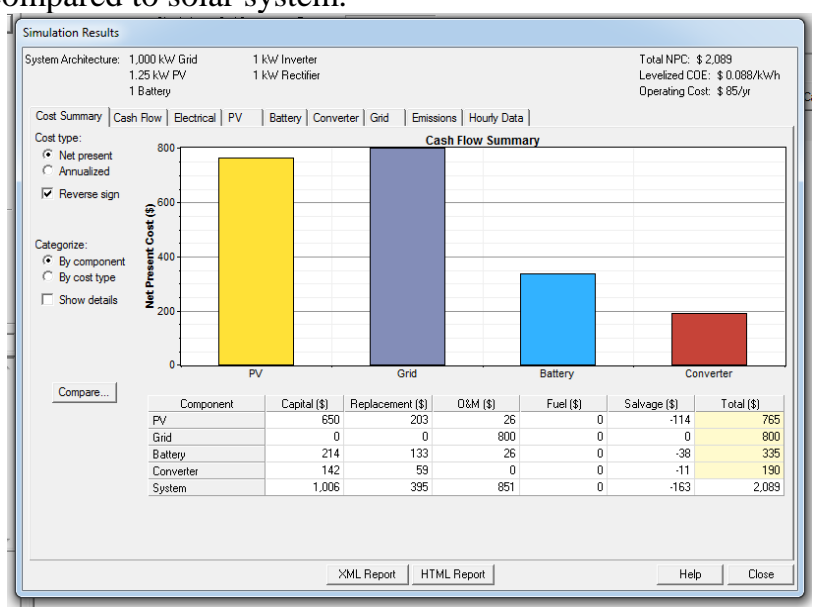

Fig No 07: Cash flow for individual arrangement of ACMG
The complete expenditure on experimental setup of AC microgrid is being explained in fig 07 which is a complete grid PV system.

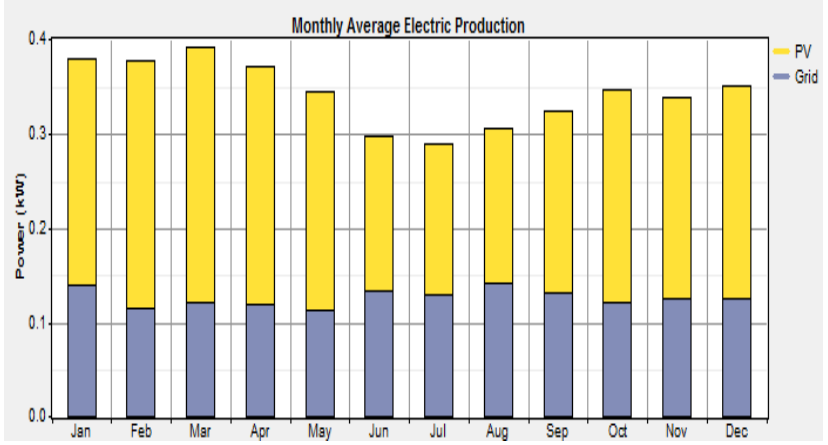

Fig No 08: Monthly Average electricity production of ACMG

Total electricity production by all the unit of sources in AC micro grid are explained in the figure number 08. From this figure we can analyze that maximum electricity is being produced by solar. During cloudy days the backup is controlled by grid system.

VII. RESULT AND DISCUSSION:

\begin{tabular}{|l|r|r|}
\multicolumn{1}{|c|}{ Production } & k'wh/yr & \multicolumn{1}{c|}{$\%$} \\
\hline Ply array & 1,898 & 86 \\
\hline Gererator 1 & 299 & 14 \\
\hline Total & 2,196 & 100 \\
\hline
\end{tabular}

Fig No 09: Cash flow for arrangement of DCMG

During analysis of DC microgrid with all setup the cash involved in the DC microgrid with units per year is 2196 which includes $1898 \mathrm{kwh} / \mathrm{yr}$ from PV system and $299 \mathrm{kwh} / \mathrm{yr}$ from Generator. Which spilts the ratio of production in 86:14.

\begin{tabular}{l|r|c|}
\multicolumn{1}{c|}{ Consumption } & \multicolumn{1}{c|}{$\mathrm{kW} / \mathrm{h} / \mathrm{r}$} & $\%$ \\
\hline DC primary load & 1,847 & 100 \\
\hline Total & 1,847 & 100 \\
\hline
\end{tabular}

Fig No 10: Unit consumption of DCMG

During the analysis of result with consumption of power with unit rate in DC microgrid the value came $1847 \mathrm{kwh} / \mathrm{yr}$. Which explains the usage of power with all DC loads. 


\begin{tabular}{l|r|l|}
\multicolumn{1}{c|}{ Quantity } & kwh/yr & $\%$ \\
\hline Excess electricity & 101 & 4.59 \\
\hline Unmet electric load & 0.00 & 0.00 \\
\hline Capacity shortage & 0.00 & 0.00 \\
\hline \multicolumn{1}{|c|}{ Quantity } & \multicolumn{2}{|c|}{ Value } \\
\hline Renewable fraction & \multicolumn{2}{|c|}{0.864} \\
\hline
\end{tabular}

Fig No 11: Renewable benefit form DCMG

With the results prodcued from Homer its very clear that from DC micro grid we can generate an excess electricy which can reuslts of extra rveune which makes the system more economical.

\begin{tabular}{|l|r|r|}
\multicolumn{1}{|c|}{ Production } & kWh/yr & \multicolumn{1}{c|}{$\%$} \\
\hline PV array & 1,898 & 63 \\
\hline Grid purchases & 1,105 & 37 \\
\hline Total & 3,003 & 100 \\
\hline
\end{tabular}

Fig No 12: Cash flow for of ACMG

The same way while analyzing AC microgrid with all setup the cash involved in the AC microgrid with units per year is 3003 which includes $1898 \mathrm{kwh} / \mathrm{yr}$ from PV system and 1105 $\mathrm{kwh} / \mathrm{yr}$ from Grid. Which splits the ratio of production in 63:37. Which is more camper to DC micro grid.

\begin{tabular}{l|r|r|}
\multicolumn{1}{c|}{ Consumption } & \multicolumn{1}{c|}{ kWh/yr } & $\%$ \\
\hline AC primary load & 1,847 & 66 \\
\hline Grid sales & 959 & 34 \\
\hline Total & 2,806 & 100 \\
\hline
\end{tabular}

Fig No 13: Unit consumption of DCMG

But while discussing about the consumption of power with unit rate in AC microgrid the value came $2806 \mathrm{kwh} / \mathrm{yr}$. Due to purchasing rate of Grid.

\begin{tabular}{|r|r|r|}
\multicolumn{1}{c|}{ Quantity } & kWh/yr & $\%$ \\
\hline Excess electricity & 1.64 & 0.05 \\
\hline Unmet electric load & 0.00 & 0.00 \\
\hline Capacity shortage & 0.00 & 0.00 \\
\hline Quantity & \multicolumn{2}{|c|}{ Value } \\
\hline Renewable fraction & \multicolumn{2}{|c|}{0.632} \\
\hline
\end{tabular}

Fig No 14: Renewable benefit form DCMG

The excess electricity which has prodcued from AC microgrid id 0.632 which is less compre to DC microgrid.

\section{CONCLUSION:}

From all kind of analysis and study the conclusion what we got is DC micro grids are more economical and reliable as renewable fraction is more. The DC micro grid is compltely standalone system which makes it more popular in rural areas and as because of reneable usage its environmenatal friendly as well.

\section{REFERENCES}

1. Chua, K. H., et al. "Energy storage system for mitigating voltage unbalance on low-voltage networks with photovoltaic systems." IEEE Transactions on power delivery 27.4 (2012): 1783-1790.

2. Liu, Liming, Yan Zhou, and Hui Li. "Coordinated active and reactive power management implementation based on dual-stage PLL method for grid-connected PV system with battery." 2010 IEEE Energy Conversion Congress and Exposition. IEEE, 2010.

3. Perez, Emilio, et al. "Predictive power control for PV plants with energy storage." IEEE Transactions on Sustainable Energy 4.2 (2012): 482-490.

4. Chakraborty, Sudipta, Manoja D. Weiss, and Marcelo Godoy Simoes. "Distributed intelligent energy management system for a single-phase high-frequency AC microgrid." IEEE Trans. Industrial Electronics 54.1 (2007): 97-109.

5. Morais, Hugo, et al. "Optimal scheduling of a renewable micro-grid in an isolated load area using mixed-integer linear programming." Renewable Energy 35.1 (2010): 151-156.

6. Furuse, Mitsuho, et al. "Feasibility study of low-voltage DC superconducting distribution system." IEEE transactions on applied superconductivity 15.2 (2005): 1759-1762.

7. Shimomachi, Kentaro, Ryoichi Hara, and Hiroyuki Kita. "Comparison between DC and AC microgrid systems considering ratio of DC load." 2015 IEEE PES Asia-Pacific Power and Energy Engineering Conference (APPEEC). IEEE, 2015.

8. Shimomachi, Kentaro, Ryoichi Hara, and Hiroyuki Kita. "Comparison between DC and AC microgrid systems considering ratio of DC load." 2015 IEEE PES Asia-Pacific Power and Energy Engineering Conference (APPEEC). IEEE, 2015.

9. Shimomachi, Kentaro, Ryoichi Hara, and Hiroyuki Kita. "Comparison between DC and AC microgrid systems considering ratio of DC load." 2015 IEEE PES Asia-Pacific Power and Energy Engineering Conference (APPEEC). IEEE, 2015.

10. Shimomachi, Kentaro, Ryoichi Hara, and Hiroyuki Kita. "Comparison between DC and AC microgrid systems considering ratio of DC load." 2015 IEEE PES Asia-Pacific Power and Energy Engineering Conference (APPEEC). IEEE, 2015.

11. Shimomachi, Kentaro, et al. "Development of energy management system for dc microgrid for office building:-day ahead operation scheduling considering weather scenarios." 2014 Power Systems Computation Conference. IEEE, 2014.

12. Shimomachi, Kentaro, Ryoichi Hara, and Hiroyuki Kita. "Comparison between DC and AC microgrid systems considering ratio of DC load." 2015 IEEE PES Asia-Pacific Power and Energy Engineering Conference (APPEEC). IEEE, 2015.

13. Sirsi, Rohan, and Yadnyesh Ambekar. "Efficiency of DC microgrid on DC distribution system." 2015 IEEE Innovative Smart Grid Technologies-Asia (ISGT ASIA). IEEE, 2015.

14. Fairley, Peter. "DC versus AC: The second war of currents has already begun [in my view]." IEEE Power and energy magazine 10.6 (2012): 104-103.

15. Salomonsson, Daniel, and Ambra Sannino. "Low-voltage DC distribution system for commercial power systems with sensitive electronic loads." IEEE Transactions on Power Delivery 22.3 (2007): 1620-1627.

16. Liu, Zifa, and Mengyu Li. "Research on energy efficiency of Dc distribution system." AASRI procedia 7 (2014): 68-74.

17. Reed, Gregory F. "DC technologies: solutions to electric power system advancements [guest editorial]." IEEE Power and Energy Magazine 10.6 (2012): 10-17.

18. Patterson, Brian T. "Dc, come home: Dc microgrids and the birth of the" enernet"." IEEE Power and Energy Magazine 10.6 (2012): 60-69.

19. Sirsi, Rohan, et al. "Efficiency comparison of AC distribution system and DC distribution system in microgrid." 2016 international conference on energy efficient technologies for sustainability (ICEETS). IEEE, 2016. 


\section{AUTHORS PROFILE}

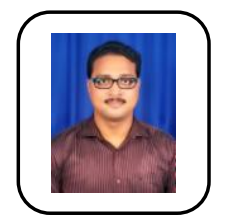

Srikant Misra received M. Tech in Power Electronics and Drives, Biju Pattnaiik University of Technology, Rourkela with First Class (2009-2011), Presently he is working as Asst. Professor in GIETU Gunupur. His area of Interest are Smart Grid, Renewable Energy Syatem.

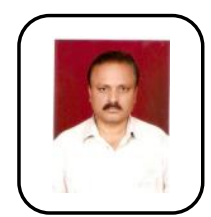

GRKD Satya Prasad received M.Tech in Electrical power systems from JNTU, Ananatapur. He is a research scholar in JNTU Kakinada and currently working as Associate professor in the Dept. of EEE in Gandhi Institute of Engineering and Technology University, GUNUPUR. He is a certified Energy Manager \& auditor (BEE, govt. of India). He is also a member of IEEE, Life member in ISTE and SESI. He has published several papers in National and International Journals and Conferences. His area of interest is Power systems, Distributed generation, Energy conservation and renewable energy systems.

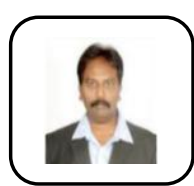

Dr. Ch. SAI BABU received B. E from Andhra University (EEE), M. Tech in EM\&ID from REC, Warangal and PhD from JNTU, Hyderabad. Currently he is working as a Professor in Dept. of EEE in JNTUCEK, Kakinada. He has published several papers in National and International Journals and Conferences. His area of interest are Power electronics, Distributed generation and renewable energy systems.

Rakesh Sahu received M. Tech in Power Electronics and Drives, Biju Pattnaiik University of Technology, Rourkela with First Class (2009-2011), Presently he is working as Asst. Professor in GIETU Gunupur. His area of Interest is Renewable Energy Syatem. 